\title{
Group Size and Social Ties in Microfinance Institutions
}

\author{
by Klaus AbBink, Bernd Irlenbusch, and ElKe RenNer
}

November 2002

\begin{abstract}
Microfinance programmes provide poor people with small loans given to jointly liable self-selected groups. Follow-up loans provide incentives to repay. In an experiment we investigate the influence of those features on strategic default. Each group member invests in an individual risky project, whose outcome is known only to the individual investor. Subjects decide, whether to contribute to group repayment or not. Only those with successful projects can contribute. The experiment ends if too few repay. We investigate group size and social ties effects. We observe high repayments rates, which are robust across treatment. Group lending outperforms individual lending. Self-selected groups show a high but less stable willingness to contribute.
\end{abstract}

\section{Keywords}

Microcredits, group lending, public goods, laboratory experiments, development economics

\section{JEL Classification Codes}

C90, H41, I38, O16, Z13

\section{Acknowledgements}

We are indebted to Christiane Metze and Tim Wenniges for valuable research assistance. We would like to thank Matthew Ellman, Mark Peacock, and seminar participants in Barcelona, Jena, Kiel and Nottingham for helpful comments and suggestions. Financial support from the European Union through the TMR research network ENDEAR (FMRX-CT98-0238) and the University of Erfurt is gratefully acknowledged.

\section{Addresses}

\begin{tabular}{ccc}
\hline Klaus Abbink & Bernd Irlenbusch & Elke Renner \\
\hline School of Economics & Lehrstuhl für Mikroökonomie \\
The University of Nottingham & Universität Erfurt \\
University Park & Nordhäuser Str. 63 \\
Nottingham NG7 2RD & 99089 Erfurt \\
United Kingdom & Germany \\
fax: +44-115-95-14159 & fax: +49-361-737-4529 \\
phone: $+44-115-95-14768$ & phone: $+49-361-737-4523$ & phone: $+49-361-737-4522$ \\
klaus.abbink@,nottingham.ac.uk & bernd.irlenbusch@uni-erfurt.de & elke.renner@uni-erfurt.de \\
\hline
\end{tabular}




\section{Introduction}

In recent years microfinance institutions (MFIs) have become one of the most important instruments in development policy. The idea of microfinance arose in the mid-70s when Mohammad Yunus started a pilot scheme lending small amounts of money to villagers in Bangladesh who, due to a lack of collateral, had no access to conventional loans. Encouraged by high repayment rates, he founded the Grameen Bank to run such schemes on a larger scale. Today the Grameen Bank lends to about 2.4 million people. Since Grameen's early successes, the concept of microcredits has spread throughout the world and a plethora of organisations providing small loans to the poor have come into being. ${ }^{1}$ Microfinance institutions are most widespread in less developed countries, although they are by no means confined to them. Microlending programmes have recently been introduced in transition economies like Bosnia and Russia and even in western economies like Canada and the United States. ${ }^{2}$ There are more than 5 million households served by microcredit schemes in the world today.

Prior to the microfinance revolution poor people's opportunities to take up loans had been severely limited. First, with few substantial possessions poor households cannot offer collateral to back up their loans. Second, the potential addressees of small loans in less developed countries often live in remote rural villages beyond the reach of the traditional banking system. Third, although loans needed for individual projects are small, their myriad nature makes monitoring and enforcement costs prohibitively high. Poor villagers' only access to credit had been through non-commercial development programmes which provided subsidised credit. However, since these schemes faced the same monitoring difficulties as traditional banks they often suffered from poor repayment rates and high costs and were typically doomed to failure for that reason.

Microfinance institutions use innovative means to overcome these problems. Though the single schemes differ vastly in their concrete implementations most of them share some main characteristics, the most prominent of which is that of group lending. ${ }^{3}$ In a typical microfinance scheme borrowers with individual risky projects form groups which apply for loans together. The whole group is liable if one or more group members default. Thus, joint liability provides an insurance against individual risks. Even if an individual project fails and some of the borrowers are unable to repay, the group as a whole might still be able to do so. In this sense joint liability serves as a substitute for collateral. Unless the individual risks are perfectly correlated, the overall risk of involuntary non-repayment can be substantially lower than with individual borrowing.

\footnotetext{
${ }^{1}$ Examples include BancoSol and PRODEM in Bolivia, Banka Rakyat and Badan Kredit in Indonesia, BRAC in Bangladesh, Pride Africa in Kenya, Tanzania and Uganda, Malawi and Uganda, FINADEV in Benin.

${ }^{2}$ See Conlin (1999), or ARMendáRIZ de Aghion and Morduch (2000) for an overview.

${ }^{3}$ Therefore, microfinance institutions are often referred to as joint liability lending institutions (JLLIs), though some institutions also give small loans to individuals with good reputation (ARMENDÁRIZ DE AGHION and MORDUCH (2000)).
} 
Compared with traditional credit programmes in less developed countries, microcredit schemes have proved to be a great success. Repayment rates leaped to levels previously unseen in less developed regions. Grameen reports repayment rates of more than $90 \%$; other programmes replicated such figures. However, the story is not without blemish: while many were successful, numerous MFI programmes have failed to live up to their promise. ${ }^{4}$ Furthermore, the ultimate goal of establishing sustainable credit schemes for the poor has not been reached, and most programmes still rely on subsidies and donations.

To improve the performance of microlending it is vital to improve the design of these schemes. Among practitioners as well as academic scholars there is a heated debate on the appropriate design of their key features. Lending to groups involves a fundamental dilemma: It may insure the credit against involuntary defaults, but individual borrower's reliance on fellow borrowers to repay the loan gives the former an incentive to free-ride. Indeed, if the success of an individual project is not sufficiently verifiable by other group members the dominant strategy for each individual is to shirk and hold others liable for own default. Being aware of this peril, MFI schemes have usually incorporated a number of safeguards, the most prominent of which is that borrower groups be self-selected. This is the case in many programmes, the expectation being that close social ties enhance peer pressure and group solidarity. In a theoretical study, BESLEY and COATE (1995) show that the possibility of inflicting social sanctions on peers helps improve repayment. ${ }^{5}$ However, the effectiveness of self-selection is not undisputed; WYDICK (1999) empirically investigates MFIs in Guatemala and finds no evidence that groups made up of acquaintances have higher repayment rates than those consisting of strangers. Social ties may even hamper repayment discipline if they lead to more "forgivingness" towards defaulters. ${ }^{6}$

Free-riding incentives may depend crucially on the size of the borrowing groups. In practice, it is unclear how far group size affects repayment rates. FINCA, the organisation which pioneered the village banking concept, lends to large borrower groups of between 10 and 50 members, and boasts repayment rates of $96 \%{ }^{7}$ On the other hand, Grameen prefers smaller groups with typically only five members, in order to keep free-riding and in-group coordination problems under control. In the academic literature, both positions have their advocates. GHATAK and GUINNANE (1999) argue that despite the insurance effect of larger groups, smaller groups are to be preferred for their better in-group co-ordination and reduced

\footnotetext{
${ }^{4}$ See e.g. CONLIN (1999).

${ }^{5}$ CONLIN (1999) argues that replicating the MFI concept in western cities requires that schemes rely less on social ties. See also WENNER (1995).

${ }^{6}$ GuINNANE (1994) conjectures that such an effect may have contributed to the failure of Irish credit co-operatives in the nineteenth century.

${ }^{7}$ FINCA's scheme differs from others with respect to the internal organisation of borrower groups. Villages in FINCA projects form self-governed groups to which the loan is given. The distribution of credit is left largely to the group members themselves.
} 
level of free-riding. ${ }^{8}$ On the other hand, BUCKLEY (1996) empirically finds that groups with ten or more members still can work effectively.

While much of the literature focuses on group size and social ties, the importance of dynamic incentives is acknowledged to a much lesser extent. In general MFIs aim at forming long term relationships with their client groups. Follow-up loans are frequently made subject to whether precious loans have been repaid. These two features are intended to encourage compliance with repayment obligations. It can be argued that this aspect of microcredit schemes is at least as important for generating repayment discipline as peer pressure between the group members. Creating dynamic incentives may become vital if microcredit schemes are to be applied to other economies. In the urban contexts of transition economies, for instance, it may be more difficult to form self-selected borrowing groups than in closer-knit rural communities. For this reason ARMENDÁRIZ DE AGHION and Murdoch (2000) argue that in such economies the focus on group-lending should be abandoned and suitable dynamic incentive schemes should be sought.

The empirical evidence on how the various design features of microcredit schemes affect their success is still limited and controversial. MURDOCH (1999) promotes the need for welldesigned experiments to identify the impact of MFI design features on their performance. However, controlled experiments in which single properties of institutions are systematically varied are difficult to carry out in the field, due to problems of data accessibility and comparability. ${ }^{9}$ Furthermore, many relevant variables, e.g. the individual project risk, are unobservable. Therefore, we introduce an alternative approach to the empirical analysis of microfinance institutions. In an interactive laboratory experiment, we can control for specific parameters and observe behaviour in simulated MFI scenarios directly. Furthermore, we can identify which factors influence behaviour by changing particular variables of the experimental environment, holding all other aspects unchanged.

As a starting point for our research agenda, we construct a stylised MFI scenario. To study free-riding behaviour connected to group lending we model a situation in which repayment depends on group solidarity alone. To implement dynamic incentives, follow-up loans are subject to full repayment in the past. In our experiment each member of a group of $n$ players invests in an individual risky project. Whether the project succeeds is known only to the individual investor. Subjects decide individually whether or not to contribute to the group repayment. However, only those with successful projects are able to contribute. The experiment ends if too few contribute, that is, if the group as a whole cannot fulfil its repayment obligation. We focus on three instrumental variables identified as crucial for MFI success: (1) The group size, which we set to $n=2, n=4$, and $n=8$ in three conditions, (2) the dynamic incentive structure, and (3) the intensity of social ties between group members. In a

\footnotetext{
${ }^{8}$ This argument is supported in empirical investigations by MOSLEY and DAHAL (1987) and DEVEREUX and FISHE (1993). Theoretical investigations into the tension between positive insurance and negative free-riding effects are provided by IMPAVIDO (1998) and ARMENDÁRIZ DE AGHION (1999).

${ }^{9}$ These difficulties are discussed in BOLNICK (1988) and HULME (2000).
} 
"group recruitment treatment" subjects already had to enrol as a group to capture the influence of social ties.

We observe a high and robust performance of group lending institutions in all our treatments. In fact repayment rates are generally higher than those achievable by individual lending. While individual contribution rates decrease slightly with larger groups, the impact of freeriding is alleviated by the greater dispersion of risks. We clearly identify the importance of dynamic incentives. Towards the end of the experiment repayment rates decrease substantially. Furthermore, we find that social ties only have a relatively moderate effect on repayment rates. Closer-knit groups have higher, but less stable repayment rates than those composed of strangers. We also observe gender effects: In our experiment women tend to contribute more than men.

\section{Related Experimental Studies}

To our knowledge laboratory experiments on microcredit institutions have not yet emerged in the literature. However, since microcredit institutions allow group members to free-ride at the cost of the group, valuable insights may be gained from the literature on public good games. In such games, each subject of a group of $n$ persons can decide to invest an amount $x$ (up to a certain limit $y$ ) in a public good. Everybody in the group of $n$ individuals receives a return of $c x$, where $c<1$, but $n c>1$. Thus, it is a dominant strategy for rational players not to invest, but the Pareto efficient solution is realised if everybody co-operates by investing the maximum amount. In experimental public good games subjects typically contribute considerable amounts but fail to reach the social optimum.

Inspired by the microfinance theme, BARR and KINSEY (2002) conduct an experiment on such a public good game in Zimbabwean villages. Though they do not aim at modelling a microfinance scenario, their research question is closely linked to common MFI practices. Many microfinance institutions target women as their clients, partly because they consider women's empowerment as a goal as such, but also because women are often seen as more reliable borrowers. ${ }^{10}$ The authors test this conjecture by analysing women's and men's behaviour in the standard public goods game. The differences they find are small, but qualitatively supportive of the MFI practice: Women tend to contribute more to the public good than men.

The study most akin to our experimental set-up is the public good experiment by SULEIMAN, WEISS, and BORNSTEIN (2002). In their study, the players' endowments $y$ are stochastic and private information. Thus, as in our design, players cannot identify whether other players' failure to contribute is due to bad luck or shirking. The authors observe less free-riding in this

\footnotetext{
${ }^{10}$ There is some evidence that women's repayment discipline is higher due to a better sense of responsibility (LEDGERWOOD 1999:38). MORDUCH (1999:1583) reports studies finding that male lending groups at Grameen have higher default rates than female groups. For critical accounts of the women-focused policy see GoETZ and SEN GuPTA (1996), and KABEER (2001).
} 
environment than in a standard public good setting with fixed endowments. Thus, players are less tempted to free-ride themselves when they cannot identify others' free-riding.

Several authors have examined the role of social factors in experimental public good games. All these studies, however, deal with symmetric situations in which endowments are the same for all and known to all players. GÄCHTER and FEHR (1999) investigate whether social approval incentives reduce free-riding behaviour in a repeated public good game. Subjects have the opportunity for social approval towards their group members after the experiment. It turned out that social approval alone could not enhance co-operation. However, if in addition subjects could familiarise themselves with each other before the experiment co-operation increases significantly. ${ }^{11}$ This suggests that ex-ante familiarity may be important in establishing co-operation. In another study VAN DIJK, SONNEMANS, and VAN WINDEN (2002), and BRANDTS, RIEDL, and VAN WINDEN (2002) investigate the development of social connectedness as a result of repeated interaction in a public good setting and find that social attachment becomes stronger after successful co-operation.

The effect of group size has been studied first by ISAAC, WALKER, and WILLIAMS (1994) in a public good experiment with $4,10,40$, and 100 participants. They find that contrary to the common conjecture contributions even increase with very large groups. A similar result is obtained by CARPENTER (2002), who compares groups of 5 and 10 subjects. However, in both studies marginal social benefits increase hugely as the group size increases, which may account for this effect. Unless there are strong synergies between the individual projects within an MFI borrowing group this is typically not a characteristic of microfinance institutions.

Unlike in most public good games mentioned above repayment in a microfinance scenario does not solely depend on the willingness but also on the ability to repay. Through no fault of their own, individuals whose project fail cannot contribute to repayment and hence they rely on the solidarity of fellow group members. Individuals' sense of solidarity is assessed in the solidarity game experimented by SELTEN and OCKENFELS (1998). Three players each roll a die to determine whether they win a prize. Winners can transfer money to losers. Contrary to the game theoretic prediction the great majority make substantial transfers where females show more solidarity than males.

None of these studies has been carried out with a microfinance background in mind. Consequently, there is no study examining group solidarity in a dynamic environment with followup benefits conditional on compliant behaviour. The incentive structure in the existing studies is quite different from a typical microfinance environment. Therefore, the findings of these studies cannot be immediately transferred to the microfinance institutions in question. Hence the need for a new experiment.

${ }^{11}$ This is in line with earlier findings by Dawes, MCTAvish, and ShakleE (1977), IsAaC, McCue, and Plott (1985), ISAAC and WALKER (1988, 1991), BOHNET and FreY (1999). Although they examine different questions, they all find that pre-play communication increases co-operation. 


\section{Model and Experimental Design}

We consider a very simple experimental set-up capturing essential features of group-lending. Since microfinance institutions come in many different forms, we were forced to make design choices. In the present study, we focus on the conflict between free-riding and group solidarity in the borrower group, thus, we assume that individual repayment cannot be enforced. To focus on the group solidarity aspect, we assume that individuals have no means of verifying the success or failure of their fellow borrowers' individual projects. ${ }^{12}$ Furthermore, by assuming that the success of the individual projects is uncorrelated, we abstract from complications that arise if risks are connected, as are, e.g., if their success depends on seasonal conditions. Finally, we consider a symmetric situation in which there are no differences in the individuals' strategic situation.

\subsection{The Model}

A group of $n$ individuals receives a loan, for the repayment of which all group members are jointly liable. The loan enables each group member to invest in an individual risky project. All projects are of the same type, and the probability of success of any given project is $5 / 6$. In case of success, the investor receives a project payoff of 420 talers (the fictitious experimental currency). If the project fails, however (the probability of which being $1 / 6$ ), the subject receives a project payoff of zero.

After all projects have been carried out, the group loan has to be repaid. For repayment to ensue, we assume that each individual is supposed to repay 210 talers, and hence the group is liable to repay a total amount of $210 n$ talers (for example, if we assume a loan of 175 talers per individual and an interest rate of $20 \%$ ). Those individuals whose projects failed cannot contribute to the repayment; to ensure that this condition pertains we assume that no investor receives income from another source and that none possesses savings which could be used to repay the loan in the eventuality that the project fails.

Individuals whose project succeeds decide whether to contribute to the group repayment. As mentioned above, information on the project's success or failure is private; no other group member can ascertain whether an individual's default is strategic or due to the failure of the project. Hence, we model an idealised scenario in which the repayment of loans must ensue in the absence of means to enforce repayment.

To model joint liability in a simple and straightforward way, the debt of $210 n$ talers is split evenly among those individuals who are able and willing to contribute. Thus, the less individuals contribute, the higher is the burden for the single contributor. Since contributions

\footnotetext{
${ }^{12}$ This is in line with the assumptions made by BESLEY and COATE (1995) in a theoretical study. The issue of peer-screening and peer-monitoring in group lending is addressed by STIGLITZ and WeISS (1981), STIGLITZ (1990), VARian (1990), GHATAK and GUINANNE (1999), ARMENDÁRIZ DE AGHION and GolLIER (2000), and GHATAK (2000).
} 
can only be financed from the current round's project payoffs, full repayment is only possible if at least half of the group members contribute.

Only if the group fulfils its repayment obligation, does the game continue into a further round, which proceeds in the same way with the same group members (A maximum of ten rounds can be played). If more than half the group members default (regardless of whether the default is strategic or due to project failure), then the group cannot repay the full amount, in which case no further rounds are played and the subjects of the group obtain no further payoffs during the experiment. With this feature, we model the practice of many MFIs which make follow-up loans conditional on the full repayment of previous loans.

After each round, players are informed about the number of contributors in the respective round (but not their identities), their own project payoff, and their round payoff (comprised of one's own project payoff minus the players' share of the repayment burden).

The game theoretic prediction, assuming that players maximise their own income, is that no contributions at all are made thus bringing play to an end after the first round. The intuition is straightforward. In the last round, it is obvious that no player would ever contribute. Now consider the penultimate round. Table 1 shows the payoff distribution a player would get given the number of other players willing and able to play, for eight-player groups $(n=8) .^{13}$ The entries in italics mark the cases in which the number of players contributing suffices for the game to reach the final round. The payoffs are composed of the (sure) payoffs in the penultimate round plus the lottery that the player gets in the final round. It can easily be seen that the payoff distribution a player gets from not contributing stochastically dominates the one he or she would obtain by contributing. This is true regardless of the actual number of other players willing and able to repay. Therefore, it can never be profitable to contribute in the penultimate round, and hence one would predict that no game enters round 10. By induction, it follows that in a subgame perfect equilibrium, no contributions are made in any round, and play will end after the first round, in which no contributions are made.

Table 1. Payoff with and without own contribution in the penultimate round $(n=8)$

\begin{tabular}{|c|c|c|c|c|c|c|c|c|}
\hline \multirow{2}{*}{ Decision } & \multicolumn{8}{|c|}{ number of other players willing and able to repay } \\
\hline & 0 & 1 & 2 & 3 & 4 & 5 & 6 & 7 \\
\hline cont. & 0 & 0 & 0 & $\begin{array}{r}420 ; 5 / 6 \\
0 ; 1 / 6\end{array}$ & $\begin{array}{r}504 ; 5 / 6 \\
84 ; 1 \% 6\end{array}$ & $\begin{array}{l}560 ; 5 / 6 \\
140 ; 1 / 6\end{array}$ & $\begin{array}{l}600 ; 5 / 6 \\
180 ; 1 / 6\end{array}$ & $\begin{array}{l}630 ; 5 / 6 \\
210 ; 1 / 6\end{array}$ \\
\hline not cont. & 420 & 420 & 420 & 420 & $\begin{array}{l}840 ; 5 / 6 \\
420 ; 1 / 6\end{array}$ & $\begin{array}{l}840 ; \quad 5 / 6 \\
420 ; \quad 1 / 6\end{array}$ & $840 ; 5 / 6$ & $\begin{array}{l}840 ; 5 / 6 \\
420 ; 1 / 6\end{array}$ \\
\hline
\end{tabular}

The entries in italics are lotteries, where each line represents one outcome. Within each line the semicolon separates the payoff and the probability of winning this payoff.

${ }^{13}$ The argument is completely analogous for $n=2$ and $n=4$. It can easily be generalised for a wide range of other parameter constellations. Notice that the argument does not require assumptions about the subject's attitude to risk. 
Through the unambiguous game theoretic property of the subgame perfect equilibrium the game draws an idealised picture of a microfinance situation in which repayment cannot be established by players' own payoff maximisation alone. Therefore, the game allows us to study the impact of joint liability in a microfinance relationship, since repayment out of group solidarity stands in sharp contrast to equilibrium behaviour.

It is worthwhile to look at a hypothetical benchmark of individual lending. A single individual can repay the loan if the project is successful. This occurs with a probability of $5 / 6$. Contrary to the case of group lending, an individual would prefer to repay in all rounds bar the last, since the benefits of future credit outweigh the short-term profits of shirking. However, since projects may fail, expected repayment rates cannot exceed $5 / 6$. Thus, while group-lending creates free-riding incentives (according the game-theoretic prediction there would be no repayment at all), the dispersion of risks makes it possible to generate higher repayment rates and more profitable loans for the lender. This, however, requires group solidarity, and one of our research questions is precisely whether group-lending mechanisms are able to outperform the benchmark of individual expected repayment rates of $5 / 6$.

\subsection{Treatments}

We designed our experiment to examine two major issues in the design of microfinance schemes. The first issue concerns the effect of different group sizes on repayment performance. In absence of strategic default, larger group sizes provide some insurance against uncorrelated individual risks. However, it is unclear how group size behaviourally affects the tendency to free-ride. If free-riding is more pronounced in larger groups, this might counteract the insurance effect of larger groups. To test for the effect of group sizes, we conducted experiments with group sizes of $n=2, n=4$, and $n=8$. $^{14}$

The second issue we address is the effect of social ties on behaviour in a microcredit group. Typically, MFI borrowers are self-selected groups whose members have known each other for some time. Thus, we induce different levels of social ties by applying two distinct recruitment techniques: In the individual recruitment (IR) treatments, subjects register individually for the experiment, thus minimising social ties between participants interacting with each other; In the group recruitment (GR) treatment, potential participants are required to register for the experiment in groups of four. The latter method, ensures that groups are self-selected, since subjects need to form groups in order to register themselves for the experiment. This method resembles the self-selection process required by real-life microlenders. As in their procedures borrower groups are formed before they enter the microfinance scheme. ${ }^{15}$ To control for the level of acquaintance between the group members, we requested the subjects to indicate the intensity of their contact to the other group members on a scale from 1 (no contact) to 7

\footnotetext{
${ }^{14}$ This roughly covers the range of most typical MFIs. Only few lend to groups with more than eight borrowers.

${ }^{15}$ When they register for our experiment, however, subjects did not know the task that they would perform. This was explained to them only in the actual session. This ensured that the state of information about the task was the same for all subjects at the outset of a session.
} 
(frequent contact), separately for each of the other group members. We distinguish between professional and private contacts. It seems plausible that social ties are more pronounced if the contacts are intensive and private. All statements were made anonymously. ${ }^{16}$

We conducted our GR treatment with a group size of $n=4$, given our concern that a group size of two would allow couples (with a common household budget) to register as a "group". If the two players effectively act as one then the social conflict is removed and the incentive structure is reversed. In fact contributing in all rounds except the last one is socially as well as individually optimal. On the other hand we did not conduct experiments with $n=8$ for practical reasons: it would have proved too difficult to find self-selected groups of eight subjects. Table 2 indicates the factorial design of our experiment, and, in brackets, the number of subjects in the corresponding treatment.

Table 2. The treatments of our experiment

\begin{tabular}{ccc}
\hline Group size & \multicolumn{2}{c}{ Recruitment method } \\
& Group & Individual \\
\hline$n=2$ & & IR2 (16) \\
$n=4$ & GR4 (32) & IR4 (28) \\
$n=8$ & & IR8 (64) \\
\hline
\end{tabular}

In brackets are the number of subjects.

\subsection{Experimental Procedures}

The experiment was conducted in the Erfurter Laboratorium für experimentelle Wirtschaftsforschung (eLab) at the University of Erfurt, Germany. Most subjects were students from various disciplines, where students of economics, law, and sociology constituted the largest fractions. To minimise presentation effects, we designed our experiment in a completely context free fashion. We presented the microfinance situation to the experimental subjects without connecting it to a microfinance story. We opted for a neutral presentation to avoid the uncontrolled effects of possible connotations raised by hypothetical stories, and to ensure best possible comparability with other experimental results.

Each session began with an introductory talk after which the written instructions were handed out to the subjects (Translations are provided in the appendix and the original text in German is available on request). The instructions were read aloud and explained in detail. After the introduction, the subjects were seated in cubicles, visually separated from one another by curtains. In the IR treatments, the cubicle numbers were randomly attributed to the subjects,

\footnotetext{
${ }^{16}$ For different research questions other techniques have been applied to study the impact of social ties. GÄCHTER and FEHR (1999) and BOHNET and FREY (1999) invite strangers, but allow subjects in one condition to get acquainted with each other in a pre-play communication stage. VAN DIJK, SONNEMANS, and VAN WINDEN (2002) and BRANDTS, RIEDL, and VAN WINDEN (2002) study the evolvement of social ties through interaction and assess social ties using psychological tests before and after play.
} 
and no subject was informed about the identity of the other players in his group. In the GR treatment, the subjects who had registered together formed a group. This was known to the subjects and further emphasised by decision sheets in different colours for the different groups in a session.

In each round, the success or failure of a project was determined through independent random draws for each subject, with a probability of one sixth for the failure of the project. Each subject rolled a die to determine his or her project's success or failure for each round. In order to overcome the difficulty of monitoring the veracity of subject's reports about their draw, we asked subjects at the very beginning of the session (before they knew the rules of the game) to roll a die ten times and to enter the outcomes in the first column of their decision sheet. Later in the experiment in each round the "losing number" which was the same for all subjects was determined by a randomly selected participant rolling a die. This number was publicly announced. All subjects whose individual number drawn in advance for this round matched the "losing number" met with the project failure and thus a project payoff of zero.

Each round proceeded as follows. The subjects were each handed one decision sheet, on which the complete history of play was presented on one page. The subjects indicated their repayment decision by ticking "Yes" or "No" boxes for the current round. After all subjects had completed their decisions, the experimenter collected the sheets. The "losing number" for the current round was then drawn. By letting the subjects make their repayment decisions before the "losing number" was drawn, we gathered decisions also in the case that an individual's project has failed. ${ }^{17}$ The experimenters computed the results of the rounds and distributed the decision sheets containing the results.

All groups in the session ${ }^{18}$ completed this procedure ten times, even when their group's play had actually ended as a result of repayment default. This ensured, first, that the constitution of the groups were not revealed by diverging duration of play (this would have distorted both anonymity and the statistical independence of the groups), and second, that a preference for a short playing time could not counteract the monetary incentives.

Immediately after the session, the subjects were paid anonymously in cash. The exchange rate was set to DM 0.02 per taler. The total earnings in the session ranged from DM 7.80 to DM 65.20 with an average of DM 25.50 for $1 \frac{1 / 2}{2}$ hours, considerably more than a student's normal hourly wage in Erfurt. One DM is equivalent to $€ 0.51$. At the time of the experiment, the exchange rate to the US dollar was approximately $\mathrm{DM} / \$ 2.10$.

We aimed at gathering eight independent observations per treatment. Since a few subjects in one session did not show up, one session in the IR4 treatment could only be conducted with 12 rather than 16 subjects, such that in this treatment, only seven independent observations

\footnotetext{
${ }^{17}$ BRANDTS and CHARNESS (2000) examine behaviour in different interactive games comparing spontaneous play and complete strategy elicitation, but find results to be unaffected. They suggest that both procedures be equivalent for low-complexity tasks.

${ }^{18}$ We conducted each session with at least two groups to ensure that subjects (in the IR treatment) could not identify which of the other subjects belong to their group.
} 
are available. Since subjects in different groups within a session did not interact with one another, each group can be treated as a statistically independent observation.

\section{Results}

The design of our experiment focuses on the impact of group size, social ties, and the dynamics of play. Most behavioural effects in our data express themselves in the overall number of contributions we observe in the treatment. However, before we conducted the experiment, we decided to also look at the contribution rates for the rounds 1-9 only. Since the game is certain to end after the tenth round, we may expect that behaviour in that round to be substantially different. To test for treatment differences, we chose to apply Fisher's twosample permutation test to all pairwise comparisons of the contribution rates in the independent subject groups.

Further, we also analyse the first round behaviour. Statistical tests on first round behaviour can be advantageous since at the very beginning of play each individual decision is a statistically independent observation.

\subsection{Repayment Performance}

Table 3 shows how many participants agreed to contribute (chose yes on the decision sheet) on average in the four treatments of our experiment. Additionally it reports average contribution rates in the first round as well as averages over the first nine rounds. In the first round, between $82.3 \%$ (treatment IR8) and $98.9 \%$ (GR4) of the subjects decide to contribute if their project turns out to be successful. The contribution rates over all rounds of the experiment are lower but still considerably high. Notice that according to the selfish equilibrium prediction we should observe no contributions at all.

Table 3. Contribution decisions and average duration of play

\begin{tabular}{lcccc}
\hline Treatment & IR2 & IR4 & IR8 & GR4 \\
\hline yes-choices in round 1 & $93.4 \%$ & $85.7 \%$ & $82.3 \%$ & $98.9 \%$ \\
yes-choices all rounds & $79.8 \%$ & $76.0 \%$ & $72.3 \%$ & $74.1 \%$ \\
yes-choices rounds 1-9 & $81.3 \%$ & $79.4 \%$ & $72.3 \%$ & $75.9 \%$ \\
average number of rounds played & 7.5 & 7.0 & 5.1 & 7.0 \\
\hline
\end{tabular}

From the lender's point of view the most interesting question regarding different MFI designs is how they affect the repayment rate. To address this question in our experimental framework one could look at the actual repayment rates realised in the sessions. However, these are highly influenced by the realisations of the random draws. Thus, we rather look at expected repayment rates, which we define as the repayment rate that the lender could expect if we 
take observed default rates as a proxy for the probability that a borrower defaults strategically. Denote by $\varphi$ the probability that a borrower is willing to repay. Then, actual repayment probability is $5 / 6 \varphi$, since he can only repay when his project is successful. Given this probability, the number of group members actually contributing is binomially distributed with a single event probability of $5 / 6 \varphi$. Thus, the expected repayment rate ERR can be computed as

$$
\operatorname{ERR}(\varphi)=\frac{\sum_{k=0}^{n / 2-1} 420 \cdot k \cdot B\left(n, k, \frac{5}{6} \varphi\right)+\sum_{k=n / 2}^{n} 210 \cdot n \cdot B\left(n, k, \frac{5}{6} \varphi\right)}{210 \cdot n},
$$

where $B$ denotes the non-cumulated binomial distribution. The repayment (in talers) in the case that less than $n / 2$ group members actually repay is given by the first sum of the numerator. In this case, the loan is only partially repaid, but those who pay must give their entire project payoff of 420 . The second sum computes the expected repayment in case that the whole loan is repaid. ${ }^{19}$

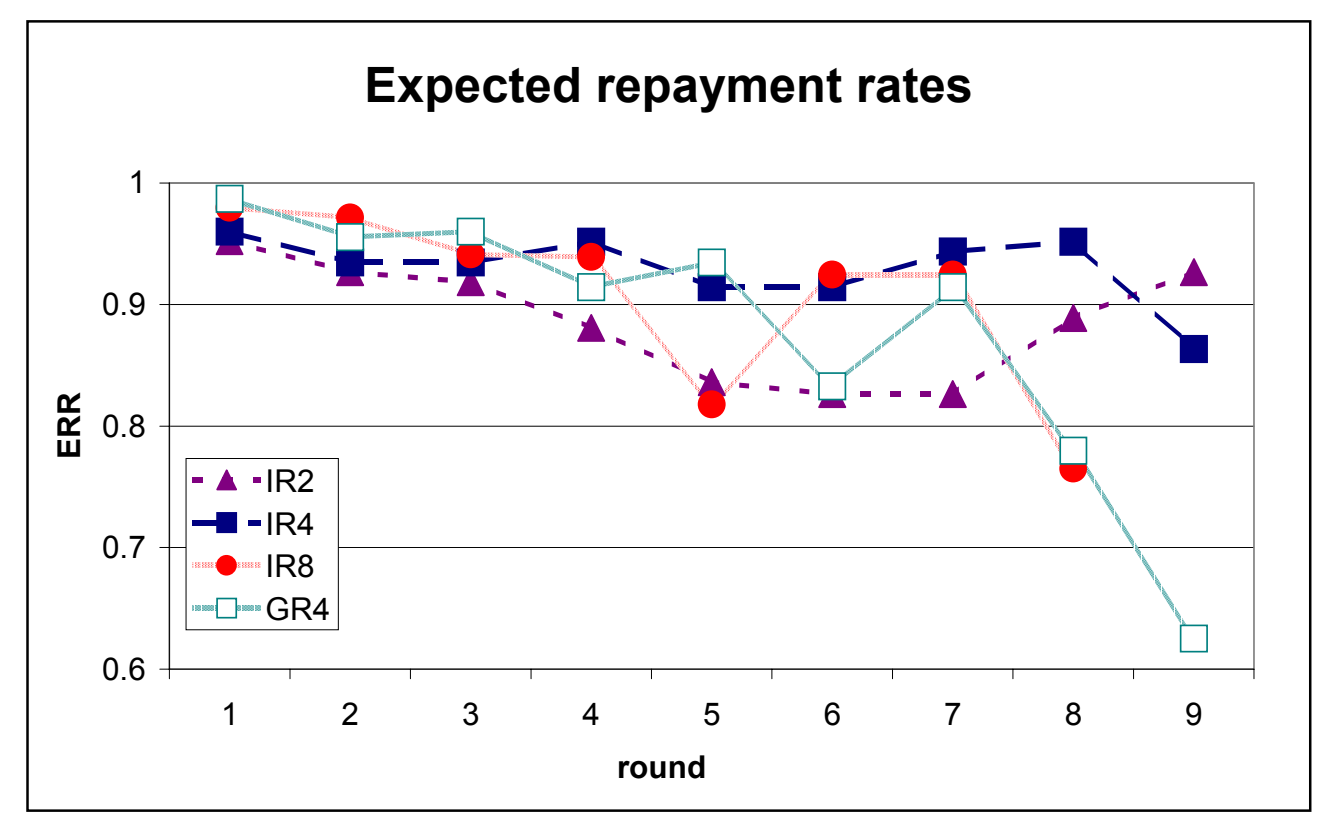

Figure 1

Figure 1 depicts the expected repayment rates for the four treatments of the experiment, using for $\varphi$ the observed rates of contribution decisions in the corresponding round and treatment.

As mentioned earlier, individual lending can at maximum generate a repayment rate of $5 / 6=83.3 \%$. Recall that according to the theoretical predictions, individual borrowers would

\footnotetext{
${ }^{19}$ The insurance effect of larger groups was principally understood by the subjects. In a post-experimental questionnaire, we asked subjects to estimate the probability to reach the final round for different group sizes $(n \in\{2,4,8\})$ and round numbers $(n \in\{5,10,20\})$ given that all group members are willing to contribute. On average the influence of the two dimensions was assessed qualitatively correct, though overall probabilities were quantitatively underestimated. The latter result replicates previous findings by GNEEZY (1996) and ABBINK, IRLENBUSCH, and RENNER (2002) in the sense that dynamic effects are not sufficiently taken into account.
} 
always, groups never repay. In our experiment, however, lenders would prefer group lending to individual lending. In all treatments, expected repayment rates are above this theoretical benchmark most of the time, and are substantially higher in earlier rounds. Thus, group lending outperforms individual lending. Even without any monitoring opportunities, trust and group solidarity can establish substantial repayment rates making group-lending advantageous to the lender.

\subsection{The Effect of the Group Size}

While large groups allow for a greater dispersion of risks one could expect that they are also prone to more free-riding. Indeed, table 3 suggests that contribution levels tend to decrease with the size of the group but only to a moderate extent. The statistical analysis provides only weak support. The non-parametric Jonckheere test, applied to the rates of yes-choices in rounds 1-9 in the single independent groups, rejects the null hypothesis of equal rates in favour of the hypothesis of decreasing rates at a weak significance level of $\alpha=0.10$ (onesided).$^{20}$ Of all pairwise comparisons, we can reject the null hypothesis of equal contribution rates only for the comparison of the contribution rates in rounds 1-9 for IR8 versus IR4. The rates tend to be weakly significantly ( $\alpha=0.10$, one-sided, Fisher's two-sample permutation test) lower in the IR 8 condition. All other differences are not statistically significant.

Table 3 also indicates a decreasing average duration of play. However, the Jonckheere test does not reject the null hypothesis of an equal number of played rounds. Notice that the continuation of play is not only determined by the subjects' decisions, but also by the chance moves determining success and failure of the individual projects.

\subsection{Dynamics of Play}

Since we have a finite number of rounds the dynamic incentives become weaker over time, as there are fewer rounds left in which profits can be made. Thus, we should expect contribution rates to decrease towards the end of play. Figure 2 shows that this is indeed the case. Though still more than two thirds of subject contribute in round 7, late round contribution rates fall substantially. However, they do not reach zero, even in the last round of play. It seems surprising that even in the last round a considerable number of subjects contribute, though no further rounds can be expected. $^{21}$

The decreasing trend of the contribution decisions can be observed not only in the aggregate data, but also in the single groups. We compute, for each session separately, non-parametric Spearman rank correlation coefficients between the number of yes-choices and rounds. Table 4 reports these rank correlation coefficients. Using these as summary statistics, the binomial

\footnotetext{
${ }^{20}$ The analysis of group size effects is based on the three treatments with individual recruitment.

${ }^{21}$ Possibly a solidarity motive accounts for this type of behaviour. If a subject expects other subjects to contribute, then own contribution can ease the fellow players' burden of repayment.
} 
test rejects the null hypothesis that positive and negative correlation coefficients are equally likely at a significance level of at least $\alpha=0.05$ (one-sided) for all four treatments. ${ }^{22}$

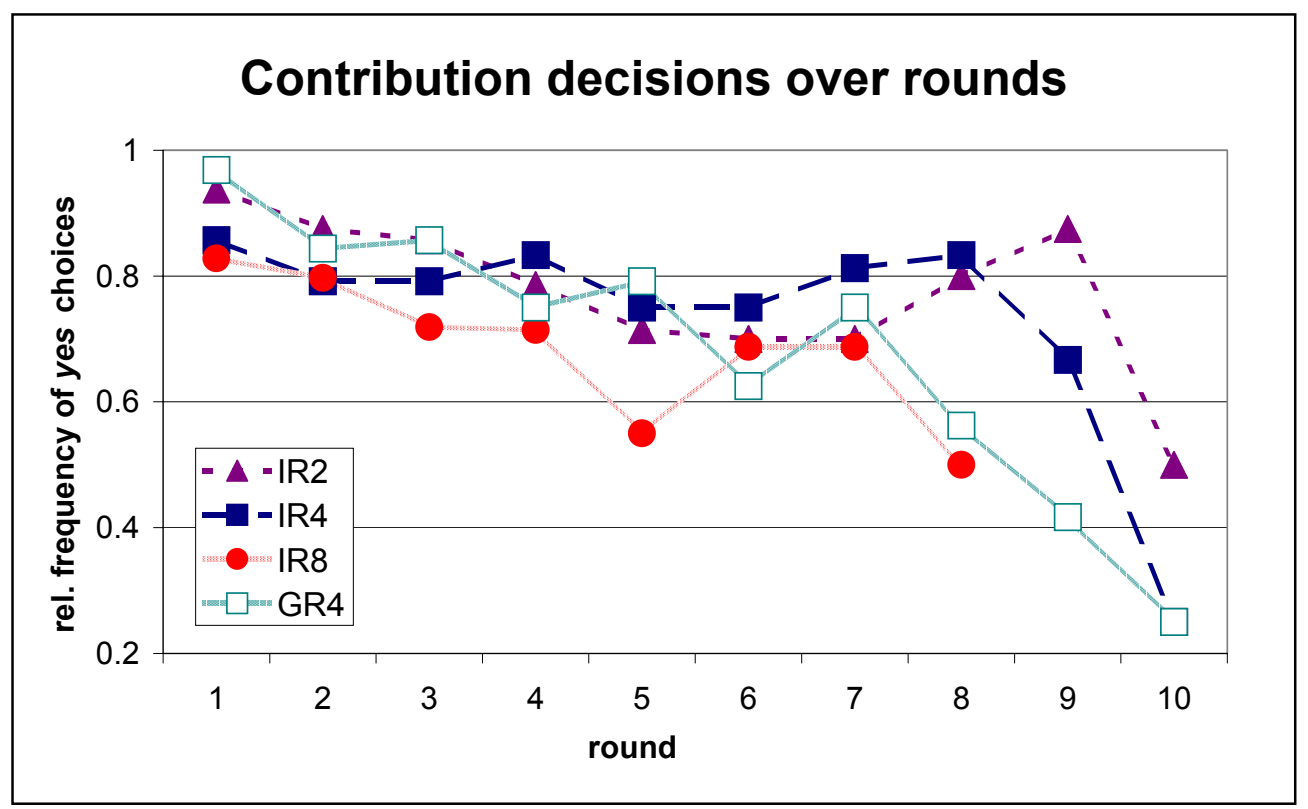

Figure 2

Table 4. Spearman rank correlation coefficients of yes-choices over the played rounds (excluding round 10)

\begin{tabular}{ccccc}
\hline \multicolumn{5}{c}{ Treatment } \\
group & IR2 & IR4 & IR8 & GR4 \\
\hline 1 & - & 0 & -0.77 & $-0.61^{*}$ \\
2 & -0.51 & -0.52 & -0.82 & $-0.88^{*}$ \\
3 & 0 & -0.62 & -0.67 & $-0.63^{*}$ \\
4 & -0.27 & - & -0.89 & -0.77 \\
5 & $-0.73^{*}$ & -0.42 & - & -0.95 \\
6 & 0 & -0.57 & $-0.98^{*}$ & -0.65 \\
7 & -0.67 & -0.75 & -0.32 & - \\
8 & -0.87 & & -0.77 & $-0.75^{*}$ \\
\hline “*” significant at $\alpha=0.05$ (one-sided) & & \\
“_" number of played rounds lower than three &
\end{tabular}

\subsection{The Effect of Social Ties}

In the GR treatment, the groups who registered together can be expected to be a self-selected group in which social ties are stronger than in the anonymously matched groups of the IR treatment. The question arises whether these stronger social ties result in higher repayment rates due to a higher impact of group solidarity in self-selected groups. Our data provide

\footnotetext{
${ }^{22}$ Notice that the exclusion of round 10 is conservative to our findings.
} 
mixed evidence with this respect. While the first round contribution rate rises from $85.7 \%$ in IR4 to $96.9 \%$ in GR4 (insignificant, $\mathrm{p}=0.12$ according to the Fisher exact test), we obtain an overall contribution rate which is even slightly lower in GR4 than in IR4 $(74.1 \%$ versus $76.1 \%$ ). Thus, the comparison of the contribution rate over the two treatments does not provide strong evidence for an effect of social ties on repayment rates. These results are in line with those of the survey study by WYDICK (1999), who finds a "surprisingly small degree to which social ties within borrowing groups affect group performance".

However, further exploration of the GR4 data indicates some support for an effect of social ties. As figure 2 indicates, the rate of yes-choices starts at a higher level in GR4, but we can observe a sharp decrease in later rounds. In the IR4 treatment, the rates of yes-choices is more stable towards the end of the experiment. If we compare the Spearman rank correlation coefficients of the yes-choices in the single groups of these two treatments, as reported in table 4, we find that the coefficients in GR4 are greater (in absolute values) than in IR4. Fisher's two-sample randomisation test rejects the null hypothesis of equal rank correlation coefficients at a significance level of $\alpha=0.01$ (one-sided). Stronger social ties seem to induce a high, but less stable willingness to repay. Possibly subjects tend to be less "tolerant" towards their peers' suspected shirking when the fellow group members are their friends. ${ }^{23}$

Within the GR4 treatment, we find some evidence that the extent to which the group members are socially tied matters. As mentioned earlier, we asked for statements about the level of acquaintance between the group members. When we correlate the level of private social contacts to the overall contribution rate in the groups, we obtain a Spearman rank correlation coefficient of $r_{S}=0.73$, which is significant at $\alpha=0.05$ (one-sided). Thus, stronger private contacts between the group members seem to have a positive effect on repayment decisions. The same analysis with the level of professional contact does not yield a significant result.

\subsection{Gender Effects}

Though the study of gender effects has not been one of our core issues at the outset of the experiment, we kept record of the gender of each participant. Table 5 shows first round and overall rates of yes-choices, for women and men separately. It can be seen that women's rate of yes-choices is higher than that of men in all treatments with individual recruiting. Fisher's exact test applied to the number of yes-choices in round 1 yields a one-sided significance level of $\alpha=0.01$, if we pool the data from all three IR treatments. ${ }^{24}$

Though the frequencies in table 5 show sizeable differences in the contribution rates of females and males, the results should be interpreted with caution. First, the relatively small

\footnotetext{
${ }^{23}$ It is well-known that subjects in public good experiments cease co-operation when they observe free-riding by other group members (see, e.g. KESER and VAN WINDEN (2000) and FALK, FISCHBACHER, and GÄCHTER (2002)). Conditional co-operation is much harder to achieve in our game since other players' shirking is not unambiguously observable. However, subjects may abandon co-operation if they feel that observed total contribution levels are suspiciously low.

${ }^{24}$ Notice that in the first round, the individual subjects can be treated as statistically independent observations.
} 
number of independent observations does not allow to comprehensively control for all possibly relevant socio-economic variables, such that we cannot detect compound effects with other background variables. Second, we can statistically detect the effect only for the pooled data of the first round data of the individual recruitment conditions, such that the evidence is relatively weak (men's contributions in the group recruitment treatment are even slightly higher). Finally, interpretations with respect to the current MFI practice to target women seem difficult, as the cultural background of our subject pool regarding gender relations might be considerably different from that in the target societies of microfinance schemes.

Table 5. Contribution decisions of women and men

\begin{tabular}{lcccc}
\hline Treatment & IR2 & IR4 & IR8 & GR4 \\
\hline yes-choices of women, first round & $100.0 \%$ & $94.7 \%$ & $90.0 \%$ & $96.2 \%$ \\
yes-choices of men, first round & $50.0 \%$ & $66.7 \%$ & $70.8 \%$ & $100.0 \%$ \\
yes-choices of women, overall & $78.4 \%$ & $80.5 \%$ & $78.8 \%$ & $77.0 \%$ \\
yes-choices of men, overall & $55.0 \%$ & $55.0 \%$ & $54.9 \%$ & $81.3 \%$ \\
\hline
\end{tabular}

\section{Summary and Discussion}

We introduce an experimental microfinance game to separate the impact of essential characteristics of group lending contracts on repayment performance. Small loans are given to groups who are jointly liable for repayment. Incentives to repay are provided through the prospect of follow-up loans. We report an experiment to investigate the influence of those features on strategic default of group members. Treatments involve different group sizes and a condition in which self-selected subject groups register for the experiment together.

We observe high willingness to repay in all treatments, though game theory would recommend free-riding. Through this high degree of solidarity, the experimental lending groups reach high repayment rates and are able to sustain the flow of further credits for several periods. The willingness to contribute declines as the experiment proceeds, but it remains remarkably high, even in the later periods, where the incentives to keep up the borrowingrelationship diminish.

We also examine the question of group size which is lively discussed in MFI policy. A dilemma arises when the advantage of larger groups through the insurance effect is counteracted by less solidarity and more free-riding. Our results show that the performance of the experimental microcredit groups is surprisingly robust with respect to group size. While the larger groups indeed manifest a higher tendency towards shirking, their superior dispersion of risk makes them perform at least as well as smaller groups in our parameter constellation. 
Our results are also robust against variations of social ties between the members of the experimental borrower groups. Overall performance is not significantly worse with strangers than with good acquaintances. Self-selected groups exhibit a higher willingness to contribute in the beginning of the experiment, but their behaviour is less stable, possibly because friends are less willing to tolerate supposed free-riding by others.

Our data exhibit a gender effect. Females show a significantly higher willingness to contribute than males which is in line with previous findings in related experimental games (SELTEN and OCKENFELS (1998)). This is also interesting as it seems to support the common practice of MFI lenders to give loans predominantly to women. However, as gender relations are different in different parts of the world, this finding should not be generalised prior to future research.

We believe that the experimental method is especially well suited to gaining a deeper understanding of how and why group lending schemes succeed or fail in practice. The present study provides a framework in which the effects of central MFI features can be disentangled. Of course, the present study should be seen as a starting point rather than a comprehensive exploration. To keep things simple, we have developed a very basic model that naturally lacks many of the complexities of real life group lending contracts. Furthermore, our experiment has been conducted in our laboratory using our student subject pool. Microfinance institutions are implemented all over the world within a great variety of economic and cultural backgrounds, such that the replication of our findings in different societies with different subject pools seems a promising research agenda for the future.

\section{References}

ABBINK, Klaus, Bernd IRLENBUSCH, and Elke RENNER (2002): An Experimental Bribery Game, Journal of Law, Economics, and Organization, 18, 428-454.

ARMENDÁRIZ DE AGHION, Beatriz (1999): On the design of a credit agreement with per monitoring, Journal of Development Economics, 60, 79-104.

ARMENDÁRIZ DE AGHION, Beatriz and Christian Gollier (2000): Peer group formation in an adverse selection model, The Economic Journal, 110, 632-643.

ARMENDÁRIZ DE AGHION, Beatriz and Jonathan MoRdUCH (2000): Microfinance beyond group lending, Economics of Transition, 8, 401-420.

BARR, Abigail, and Bill KINSEY (2002): Do Men Really have no Shame? Working paper, University of Oxford.

BESLEY, Timothy and Stephan COATE (1995): Group lending, repayment incentives and social collateral, Journal of Development Economics, 46, 1-18.

BOHNET, Iris and Bruno S. FREY (1999): The sound of silence in prisoner's dilemma and dictator games, Journal of Economic Behavior and organization, 38, 43-57.

BoLNIK, Bruce R. (1988): Evaluating Loan Collection Performance: An Indonesian Example, World Development, 16, 501-510.

BRANDTS, Jordi and Gary ChARNeSS (2000): Hot vs. Cold: Sequential Responses and Preference Stability in Experimental Games, Experimental Economics, 2, 227-238.

BrandTS, Jordi, Arno RiedL and Frans VAN Winden (2002): Competitive Rivalry and Social Ties. An Experimental Study, mimeo. Institut d'Anàlisi Econòmica (CSIC), Barcelona.

BUCKLEY, Graeme (1996): Rural and agricultural credit in Malawi: A study of the Malawi Mudzi Fund and the smallholder agricultural credit administration, in: David Hulme and Paul Mosley (eds): Finance Against Poverty, London: Routledge.

CARPENTER, Jeffrey P. (2002): Punishing Free-Riders: how group size affects mutual monitoring and the provision of public goods, Middlebury College Working Paper Series No. 0206. 
Conlin, Michael (1999): Peer group micro-lending programs in Canada and the United States, Journal of Development Economics, 60, 249-269.

DAWES, Robyn M., Jeanne MCTAVISH and Harriet SHAKLEE (1977): Behavior, communication, and assumptions about other people's behavior in a commons dilemma situation, Journal of Personality and Social Psychology, 35, 1-11.

DevereuX, JoHn and, Rauymond P.H. Fishe (1993): An Economic Analysis of Group Lending Programs in Developing, Developing Economies, 31, 102-121.

FALK, Armin, Urs FISCHBACHER, and Simon GÄCHTER (2002): Isolating Social Interaction Effects - An Experimental Investigation, mimeo, University of St. Gallen.

FEHR, Ernst and Simon GÄCHTER (2000): Cooperation and Punishment in Public Goods Experiments, American Economic Review 90, 980-994.

GÄCHTER, Simon and Ernst FEHR (1999): Collective action as a social exchange, Journal of Economic Behavior and organization, 39, 341-369.

GHATAK, Maitreesh (2000): Screening by the company you keep: Joint liability lending and the peer selection effect. The Economic Journal, 110, 601-631.

GHATAK, Maitreesh and Timothy W. GuINNANE (1999): The economics of lending with joint liability: theory and practice, Journal of Development Economics, 60, 195-228.

GNEEZY, Uri (1996): Probability judgments in multi-stage problems: Experimental evidence of systematic biases, Acta Psychologica, 93, 59-68.

Goetz, Anne Marie and Rina Sen GuPTA (1996): Who Takes The Credit? Gender, Power and Control over Loan Use in Rural Credit Programmes in Bangladesh, World Development, 24, 45-63.

GuINNANE, Timothy W. (1994): A failed institutional transplant: Raiffeisen credit cooperatives in Ireland 18941914, Explorations in Economic History, 31, 38-61.

Hulme, David (2000): Impact Assessment Methodologies for Microfinance: Theory, Experience and better Practice, World Development, 28, 79-98.

IMPAVIDO, Gregorio (1998): Credit rationing, group lending and optimal group size, Annals of Public and Cooperative Economics, 69, 243-260.

ISAAC, R. Mark and James M. WALKER (1988): Communication and free riding behavior: the voluntary contribution mechanism, Economic Inquiry, 26, 585-608.

ISAAC, R. Mark and James M. WALKER (1991): Costly communication: An experiment in nested public goods problem, in: Laboratory Research in Political Economy, Thomas Palfrey (ed.), Ann Arbor University of Michigan Press, 269-286.

ISAAC, R. Mark, Kenneth F. MCCUE and Charles R. PlotT (1985): Public goods provision in an experimental environment, Journal of Public Economics, 26, 51-74.

ISAAC, R. Mark, James M. WALKER and Arlington W. Williams (1994): Group Size and the voluntary provision of public goods, Journal of Public Economics, 54, 1-36.

KaBEER, Naila (2001): Conflicts Over Credit: Re-Evaluationg the Empowerment Potential of Loans to Women in Rural Bangladesh, World Development, 29, 63-84.

KESER, Claudia and Frans VAN WINDEN (2000): Conditional Cooperation and Voluntary Contributions to Public Goods, Scandinavian Journal of Economics 102, 23-29.

LEDGERWOOD, Joanna (1999): Microfinance Handbook. World Bank, Washington D.C.

MORDUCH, Jonathan (1999): The microfinance promise, Journal of Economics Literature, 37, 1569-1614.

Mosely, Paul and Rudra Prasad Dahal (1987): Credit for the Rural Poor: A Comparison of Policy Experiments in Nepal and Bangladesh, Manchester Papers on Development, 3, 45-59.

SELTEN, Reinhard and Axel OCKENFELs (1998): An experimental solidarity game, Journal of Economic Behavior and Organization, 34, 517-539.

STIGLITZ, Joseph E. and Andrew WeISs (1981): Credit Rationing in Markets with Imperfect Information, The American Economic Review, 71, 393-410.

Stiglitz, Joseph E. (1990): Peer monitoring and credit markets. World Bank Economic Review, 4, 351-366.

SuleimAn, Ramzi , Taly WeISS and Gary BorNSTEIN (2002): The Enhancing Effect of Uncertainty about Individual Endowments on the Provision of Public Goods, mimeo, Hebrew University Jerusalem

VARIAN, Hal R. (1990): Monitoring Agents with Other Agents, Journal of Institutional and Theoretical Economics, 146, 153-174.

VAN DiJK, Frans, Joep SONNEMANS and Frans VAN WINDEN (2002): Social Ties in a Public good Experiment. Journal of Public Economics, 85, 275-299.

WENNER, M. (1995): Group credit. A means to improve information transfer and loan repayment performance. Journal of Development Studies, 32, 263-281.

WYDICK, Bruce (1999): Can social Cohesion be harnessed to repair market failures? Evidence from group lending in Guatemala, The Economic Journal, 109, 463-475. 


\section{Appendix. The Written Instructions}

\{Original instructions were written in German. They are available upon request from the authors. The following instructions are those for the treatment IR8. The instructions for the treatments IR2 and IR4 differ only in the corresponding numbers. The instructions for treatment GR4 contain one different sentence which is indicated below.

\section{Experimental Instructions}

During the experiment you belong to a group consisting of 8 randomly chosen members.

\{GR4 treatment: During the experiment you belong to a group consisting of the 4 members with whom you have registered $\}$.

The composition of each group does not change throughout the experiment.

The experiment starts with the first round. Whether there will be a following round depends on the group's result of the previous round. A maximum of 10 rounds are played.

\section{Contribution to the group payment?}

In every round, each member of a group decides whether to contribute to a group payment or whether not to contribute.

In each round, the group has to raise a total amount of 1680 talers in order to reach a further round.

\section{Who is able to pay and who pays how much?}

For each group member it is randomly determined whether he receives an amount of 420 Taler. For this, in every round the experimenter asks a randomly chosen participant to roll a die. If the number is identical to the number for the respective round, which a participant has written down in the first column before the beginning of the experiment, this participant receives $\mathbf{0}$ talers. If the numbers do not match, the participant receives $\mathbf{4 2 0}$ talers. Thus, the decision whether a participant receives $\mathbf{4 2 0}$ talers takes place at random and independently ofall other participants.

A group member can only contribute to the group payment if he has received 420 talers in this round. A group member who has 0 talers cannot contribute. His payoff is 0 talers.

The amount of 1680 talers that must be raised by the group will be divided equally between those group members who decided to contribute to the group payment and who in addition are able to contribute, i.e. have received 420 talers. The more members of a group are willing and able to contribute, the less is the amount each member has to pay. This amount will be subtracted from the 420 talers received by each paying member.

The contributions and round payoffs of a paying member result as follows:

\begin{tabular}{|l|l|l|c|}
\hline $\begin{array}{l}\text { Number of paying } \\
\text { group members }\end{array}$ & $\begin{array}{l}\text { Contribution per } \\
\text { paying member }\end{array}$ & Group raises 1680 talers? & $\begin{array}{l}\text { Round payoff for a } \\
\text { paying member }\end{array}$ \\
\hline 0 & - & No $\rightarrow$ no further round & \\
\hline 1 & 420 & No $\rightarrow$ no further round & $\mathbf{0}$ \\
\hline 2 & 420 & No $\rightarrow$ no further round & $\mathbf{0}$ \\
\hline 3 & 420 & No $\rightarrow$ no further round & $\mathbf{0}$ \\
\hline 4 & 420 & Yes $\rightarrow$ further round & $\mathbf{8 4}$ \\
\hline 5 & 336 & Yes $\rightarrow$ further round & $\mathbf{1 4 0}$ \\
\hline 6 & 280 & Yes $\rightarrow$ further round & $\mathbf{1 8 0}$ \\
\hline 7 & 240 & Yes $\rightarrow$ further round & $\mathbf{2 1 0}$ \\
\hline 8 & 210 & Yes $\rightarrow$ further round & \\
\hline
\end{tabular}

All members who have received 420 talers and have decided not to contribute to the group payment obtain this 420 talers as the payoff for this round. 


\section{Structure of the experiment}

The structure of all rounds is identical. Each group member decides whether he wants to contribute to the group payment by ticking „yes“ or ",no" in column 2 of the decision sheet. The decision is taken only for the current round. Thus, please tick only the box which corresponds with the current round, but not those for the following rounds.

The experimenters collect all decision sheets and a randomly chosen participant rolls a die. This number is publicly announced and recorded in column 3 by the experimenter. The provisional round payoff results as explained above (column 4): if the numbers of column 1 and 3 match, the group member receives 0 for this round; if the numbers differ he receives a provisional round payoff of 420 . The experimenter determines the number of paying group members (column 5) and writes down the final round payment for each member in column 6. Column 7 informs whether the group succeeded in raising the amount of 1680 talers, and the experiment continues with the next round.

For each participant the total payoff is determined (in talers) at the end of the experiment and is converted into DM at an exchange rate of $2.00 \mathrm{DM}$ per 100 talers. Additionally each participant receives an amount of 5.00 DM.

The total amount is paid in cash to each participant at the end of the experiment.

\section{Please note:}

All decisions are made anonymously, i.e. at the end of a round each member is only informed about his own decision, his own payoff and the number of paying group members. During the experiment all participants sit in a cubicle. No conclusions can be drawn regarding the identity of the other group members, their decisions or payoffs.

To make sure that anonymity is guaranteed, it is necessary to adhere to the following rules:

During the experiment it is forbidden to speak or to communicate in any way. All members are asked to stay in their cubicles till the end of the experiment.

Even if in a round a group does not succeed in raising the amount of 1680 talers, which means that no further rounds are taking place for this group, all participants have to stay in their cubicles until the end of the experiment. The experimenters continue to hand out and to collect the decision papers also for this group. Of course, those group members do not have to take decisions anymore. 



\section{Decision sheet}

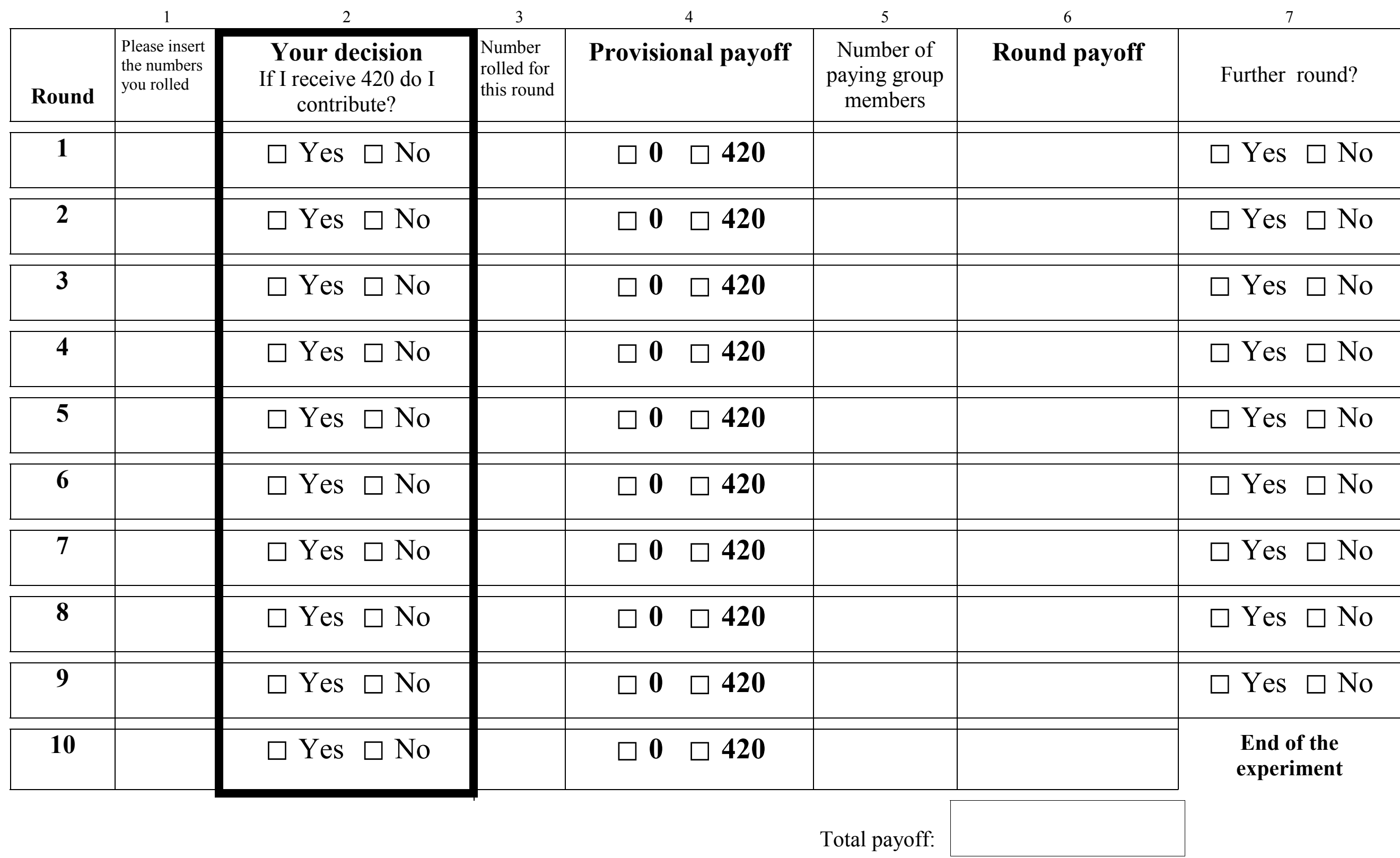

